\title{
A MOBILIZAÇÃO DE CAPACIDADES DINÂMICAS NA LOJAS RENNER
}

\section{RESUMO}

Este artigo tem como objetivo analisar a trajetória de uma das empresas varejistas de maior destaque no mercado brasileiro, por meio de um estudo longitudinal que enfatiza a mobilização de seus recursos e capacidades ao longo de 90 anos de história. Explorando o conceito de capacidades dinâmicas, descrevem-se as ações estratégicas empreendidas em momentos de crescimento e de crise. Para tanto, foram realizadas entrevistas em profundidade com dez tomadores de decisão que vivenciaram diferentes momentos da história da empresa e que desempenharam distintos papéis nos últimos 50 anos. Além disso, dado o aspecto histórico da pesquisa, especial ênfase foi dada à obtenção e à análise de dados secundários. Boletins internos, comunicados ao mercado de capitais, relatórios anuais, demonstrações financeiras, artigos da mídia, entre outras fontes, totalizaram cerca de 600 páginas de material analisado. No que diz respeito às contribuições teóricas, esta pesquisa identificou a existência de quatro mecanismos de mobilização das capacidades dinâmicas: a alavancagem, a criação, o acesso e a liberação de recursos e de capacidades. Com relação às implicações gerenciais, mostrou-se, por meio deste estudo, que habilidades dos gestores vinculadas seletivamente aos quatro mecanismos de mobilização se tornam essenciais na condução de uma empresa em seus momentos, tanto de estabilidade e crescimento, quanto de turbulência.

Palavras-chave: Capacidades dinâmicas; Estratégia; Recursos.

\section{THE MOBILIZATION OF DYNAMIC CAPABILITIES: THE CASE OF LOJAS RENNER}

\begin{abstract}
This article analyzes the trajectory of one of the most successful retail firms in Brazil. A longitudinal analysis was performed by describing the mobilization of resources and capabilities during the history of over 90 years of the firm. By exploring the concept of dynamic capabilities, it was possible to describe strategic decisions and actions made during different periods of growth and crisis. The methodological design of the research was twofold. First, primary data were collected from interviews with ten top executives that conducted the firm during the last 50 years. Second, an extensive collection of documents were analyzed, including internal notes, releases, annual reports, communications to stockholders, articles in the press, and others, with a total of 600 pages of raw material. Concerning the main theoretical contributions of the article, it was possible to identify four mechanisms of mobilization of dynamic capabilities: leverage, creation, access, and release of resources and capabilities. With respect to the managerial implications, the study showed that the selective ability of decision makers in linking together the four mobilization mechanisms are essential in periods of stability and turbulence.
\end{abstract}

Keywords: Dynamic Capabilities; Resources; Strategy. 


\section{LA MOVILIZACIÓN DE CAPACIDADES DINÁMICAS EN "LOJAS RENNER"}

\section{RESUMEN}

El artículo tiene como objetivo analizar la trayectoria de una de las empresas detallistas de mayor destaque en el mercado brasileño, a través de un estudio longitudinal que enfatiza la movilización de sus recursos y capacidades a lo largo de 90 años de historia. Explorando el concepto de capacidades dinámicas, se describen las acciones estratégicas emprendidas en momentos de crecimiento y de crisis. Para tanto, se han realizado entrevistas en profundidad con diez tomadores de decisión que han vivenciado diferentes momentos de la historia de la empresa y que han desempeñado distintos roles en los últimos 50 años. Además dado el aspecto histórico de la investigación, especial énfasis se ha dado a la obtención y al análisis de datos secundarios. Boletines internos, comunicados al mercado de capitales, informes anuales, demostraciones financieras, artículos de la media, entre otras fuentes, totalizaron cerca de 600 páginas de material analizado. Respecto a las contribuciones teóricas, la investigación ha identificado la existencia de cuatro mecanismos de movilización de las capacidades dinámicas: el apalancamiento, la creación, el acceso y la liberación de recursos y capacidades. Con relación a las implicaciones gerenciales, el estudio muestra que habilidades de los gestores vinculadas selectivamente a los cuatro mecanismos de movilización se hacen esenciales en la conducción de una empresa en sus momentos tanto de estabilidad y crecimiento como de turbulencia.

Palabras clave: Capacidades Dinámicas; Estrategia; Recursos.

Adalberto Escalona Gonçalves Garcia ${ }^{1}$ Luiz Paulo Bignetti ${ }^{2}$

\footnotetext{
${ }^{1}$ Doutor em Administração de Empresas pela Universidade do Vale do Rio dos Sinos - UNISINOS. Professor da Escola Superior de Propaganda e Marketing - ESPM. Brasil. E-mail: escalona@ cpovo.net

${ }^{2}$ Doutor em Administração pelo Ecole des Hautes Etudes Commerciales, Canadá. Professor da Universidade do Vale do Rio dos Sinos - UNISINOS. Brasil. E-mail: $\underline{\text { bignetti@ unisinos.br }}$
} 


\section{INTRODUÇÃO}

A discussão sobre as fontes de vantagens competitivas adquiridas pelas empresas tem, tradicionalmente, se baseado em duas correntes principais. De um lado, se colocam os estudos que realçam a importância da estrutura do setor a que pertence a empresa e o seu posicionamento com relação à dualidade produto/mercado (Ansoff, 1977; Porter, 1986). Assim, nessa perspectiva, a competitividade se vincularia diretamente às forças externas e à posição da empresa em relação a tais forças. De outro, há estudos que enfatizam a importância das ações internas da empresa e da mobilização eficiente de recursos. A Visão Baseada em Recursos (Barney, 1991; Wernerfelt, 1984) abriga grande parte desses estudos e se revela como uma das mais proeminentes correntes do pensamento estratégico. Uma formulação derivada dessa visão se consolidou a partir do conceito de Capacidades Dinâmicas (CD), desenvolvido por Teece, Pisano \& Shuen (1997).

O propósito deste estudo é avançar nas questões conceituais e empíricas relacionadas ao tema das capacidades dinâmicas. Para tanto, realizou-se um estudo de caso em profundidade envolvendo a análise da trajetória de mais de 90 anos de uma importante empresa varejista brasileira e apuraram-se os momentos nos quais ela fez uso de capacidades dinâmicas. O desaparecimento de empresas de grande porte no Brasil, entre 1973 e 2005, atingiu, em alguns setores, mais de $80 \%$ (Arruda et al., 2007). Um dos mais afetados pela mortalidade empresarial foi 0 varejo. Muitas empresas tradicionais desse segmento não enfrentaram adequadamente as turbulências macroambientais e setoriais, não se ajustaram às modificações nas preferências dos consumidores e, também por esses motivos, pereceram ao longo da trajetória. Como exemplo, podem ser citadas as redes Mappin e Mesbla. Outras superaram dificuldades e prosperaram. Foi o caso, por exemplo, das redes Renner, Riachuelo e Marisa, que atuam no país desde 1922, 1947 e 1948, respectivamente.

A mais antiga delas, a Lojas Renner (LR), fundada em 1922, foi escolhida para estudo devido à peculiaridade de sua história. A sua trajetória de sucesso até o final dos anos 1970, o seu declínio nos anos 1980 e a recuperação a partir dos anos 1990 despertaram o interesse dos autores para o caso. A recuperação envolveu trocas no comando, venda de ativos e reposicionamento mercadológico, entre outras ações. A eficácia das escolhas realizadas pela LR a partir de 1990 se reflete nos seus resultados financeiros. Desde 1992, a Empresa vem apresentando evolução nos indicadores de liquidez, de margem e de rentabilidade, destacando-se entre as líderes do setor no Brasil. Em 2012, a LR foi considerada a segunda marca mais valiosa do varejo brasileiro e a primeira do segmento especializado em moda, segundo os critérios da Interbrand. Tais elementos tornam a LR um caso relevante, merecedor de ser estudado.

Este artigo traz duas principais contribuições. Primeiro, ao analisar os momentos e a forma como a LR mobilizou suas capacidades dinâmicas, contribui para evidenciar que estudos sobre o tema podem não se configurar como tautológicos, como algumas vezes apresentado na bibliografia. Pelo contrário, em determinados momentos e ambientes, as capacidades dinâmicas adquirem características que são identificadas em processos organizacionais tradicionais relacionados a ações como a realização de escolhas quanto ao desenvolvimento de produtos e de mercados e à formação de alianças. A segunda contribuição do artigo é enfatizar habilidades gerenciais relacionadas à leitura do ambiente de negócios, à interpretação das necessidades dos clientes e à efetiva compreensão do nível de serviços que os recursos podem gerar. Afinal, o desempenho organizacional não é resultado apenas da posse de recursos, mas, também, é fruto das ações e das habilidades gerenciais em adequadamente mobilizar e sincronizar tais recursos.

\section{APRECIAÇÃO SOBRE O CONCEITO DE CAPACIDADES DINÂMICAS}

Teece, Pisano e Shuen introduziram o conceito de capacidades dinâmicas em 1997. Para esses autores, essas capacidades permitem às organizações integrar, construir e reconfigurar competências tendo como objetivo melhor lidar com as rápidas mudanças do ambiente. Para Helfat et al. (2007), o conceito de capacidades dinâmicas inclui identificação de necessidades (ou oportunidades), a formulação e a implementação das ações organizacionais. Envolve não apenas identificar o que fazer, mas como e quando fazer. Segundo os referidos autores, as capacidades poderiam ser divididas em organizacionais e dinâmicas. Enquanto aquelas sustentam as empresas no presente, estas dizem respeito à mudança e à sustentação organizacional no longo prazo. Capacidades dinâmicas estão vinculadas a ações propositais, ou seja, envolvem desejo de estender e modificar a base de recursos (Helfat \& Peteraf, 2009). Nesse mesmo sentido, Zollo \& Winter (2002) também evidenciam opinião de que as capacidades dinâmicas envolvem um padrão organizacional que é invocado de forma repetida e não de forma esporádica. Se as mudanças ocorrem de forma esporádica, não intencional, sem um padrão de procedimentos que sinalize a intenção de mudar, tais mudanças não são provocadas por capacidades dinâmicas. Assim, o conceito de capacidades dinâmicas parece envolver a capacidade organizacional de intencionalmente criar, ampliar e modificar a base de recursos da organização (Helfat et al., 2007). Essas mudanças, no conjunto de 
recursos da firma, podem ocorrer por meio da alavancagem dos recursos existentes ou pela criação, liberação ou acesso a novos recursos (Danneels, 2010). Se a base de recursos de uma organização, permite que a sua estratégia seja colocada em ação, as capacidades dinâmicas permitem lidar, gerenciar tais recursos (Martins et al., 2013).

Para Eisenhardt \& Martin (2000), o padrão estrutural das capacidades dinâmicas varia de acordo com o dinamismo do mercado. Assim, mercados moderadamente competitivos aceitam capacidades dinâmicas envolvendo padrões de procedimentos mais incrustados, relacionados ao desenvolvimento de processos organizacionais perfeitamente identificáveis, tais como rotinas de desenvolvimento de produtos e de desenvolvimento de alianças, que permitem às empresas identificar, aplicar e replicar conhecimento. Já para o caso de mercados mais dinâmicos, as rotinas tornam-se frágeis, mudam com maior frequência, e isso exige mais das organizações em termos de adaptação. Para os autores, são os recursos que, se adequadamente configurados e reconfigurados de acordo com as novas exigências, garantem vantagem competitiva de longo prazo.

Ao definir capacidades dinâmicas, Teece, Pisano \& Shuen (1997) usam os termos adaptação, integração e reconfiguração de habilidades organizacionais internas e externas. Para os autores, a vantagem competitiva requer o aproveitamento das capacidades já existentes (exploitation) e o desenvolvimento de novas capacidades (exploration), tudo de forma simultânea, sugerindo que tais termos, exploration e exploitation, são a base das capacidades dinâmicas. Nesse sentido, Winter (2003) evidencia que há um consenso na literatura de que as capacidades dinâmicas contrastam com as capacidades operacionais, por aquelas estarem relacionadas com mudanças, enquanto estas estão relacionadas com a manutenção do status quo. O mesmo autor evidencia que as organizações que investem no desenvolvimento de capacidades dinâmicas são aquelas que tipicamente apresentam estruturas de custos diferentes, já que o desenvolvimento de tais capacidades exige comprometimentos de longo prazo em termos de recursos. Se, de um lado, desaparecem os custos extraordinários com a solução de problemas ad hoc e surgem as economias decorrentes da eficiência, de outro, aparecemos custos de sustentação estrutural das capacidades dinâmicas (pessoas, equipamentos, softwares, projetos de pesquisa e desenvolvimento, etc.). Entende-se, portanto, que o conceito de capacidades dinâmicas está fortemente associado com a habilidade de simultaneamente lidar com o tradicional e com o emergente, os clássicos exploitation e exploration (March, 1991), e associado a padrões de comportamento organizacional, no sentido de, continuadamente, buscar a adaptação desses dois elementos. Gerir o tradicional e o emergente requer habilidade de adequadamente tratar das tensões daí decorrentes. Tais tensões (ou conflitos) não podem ser eliminadas, já que isso implicaria, necessariamente, escolher entre um dos dois elementos (tradicional ou emergente).

Tão importante quanto descobrir os recursos que uma empresa possui e apurar seu valor, a sua raridade e a sua dificuldade de imitar, é identificar o que ela faz com tais recursos. Em outras palavras, se é capaz de identificar e explorar todo o potencial de seus recursos, e se poderá continuar explorando-os, no futuro, do mesmo modo atual ou mediante outras aplicações (Hansen, Perry \& Reese, 2004). Um dos primeiros procedimentos para o exercício de capacidades dinâmicas é realizar uma adequada avaliação dos serviços que os recursos podem prestar, pois pode haver uma desconexão entre os efetivos serviços que os recursos podem oferecer e o que os gerentes pensam que eles podem proporcionar (Danneels, 2010). A produtividade dos recursos depende não apenas dos recursos em si, mas das ações e das habilidades gerenciais em identificá-los e mobilizá-los.

Apesar de sua importância, a perspectiva das capacidades dinâmicas não deixa de ser criticada. Este conceito tem sido considerado tautologicamente vago e diretamente vinculado ao sucesso, destacando-se que seus construtos fundamentais ainda não estão organizados de forma apropriada (Williamson, 1999), favorecendo, assim, a existência de lacunas empíricas (Priem \& Butler, 2001). Apesar de ser um conceito bastante atraente, o mesmo é também considerado um tanto vago e esquivo, tendo, até agora, se evidenciado altamente resistente à observação e à medição (Kraatz $\&$ Zajac, 2001). O fato de ainda apresentar um limitado subconjunto de testes empíricos empregando a abordagem também é observado na literatura (Newbert, 2007). No contexto brasileiro, pesquisa realizada por Picoli, Souza \& Takahashi (2013) em 26 periódicos nacionais da área de administração, cobrindo o período 1997 - 2012, identificou 19 artigos tratando sobre esse tema. Para os autores, a baixa quantidade de artigos apurados indica que esse tema ainda está na sua infância e que os pesquisadores brasileiros ainda direcionam esforços para compreendê-lo melhor.

Dessa discussão, depreende-se que, para o estudo das capacidades dinâmicas, e fugindo da tautologia, duas questões fundamentais devem ser abordadas. Em primeiro lugar há a necessidade de se indagar como as capacidades dinâmicas são mobilizadas. Nesse sentido, vislumbram-se os quatro mecanismos de mobilização: a alavancagem, a criação o acesso e a liberação de recursos e capacidades (Danneels, 2010; Eisenhardt \& Martin, 2000). Em segundo lugar, a outra indagação que se apresenta é sobre as habilidades gerenciais necessárias à mobilização de capacidades dinâmicas. A implementação de mecanismos relacionados com a alavancagem, a criação, o acesso e a liberação de recursos exige habilidades superiores da equipe gerencial, sem as quais o processo de renovação não se completa. 
Ao avaliar o processo de mobilização de capacidades dinâmicas em um estudo longitudinal, envolvendo o caso de uma organização de destaque no cenário nacional, que cresceu, enfrentou crises, reposicionou-se e elevou-se à posição de a mais valiosa marca do varejo brasileiro especializado em moda, o estudo pretende lançar luzes sobre tais indagações. Os procedimentos metodológicos adotados para tanto são apresentados no item três.

\section{MÉTODO}

Os dados que fundamentam este estudo foram coletados de fontes primárias e secundárias. Os dados primários foram obtidos por meio de entrevistas em profundidade, realizadas com atores que vivenciaram diferentes momentos da história da LR e desempenharam distintos papéis na Empresa, nos últimos 50 anos. As entrevistas tiveram duração entre uma e duas horas e os entrevistados apresentaram considerações sobre eventos ocorridos durante seus respectivos mandatos. A figura 1 destaca os cargos ocupados pelos entrevistados, bem como a razão da sua seleção. Optou-se por não revelar o nome dos entrevistados para manter o sigilo acerca da fonte de informação.

Pelo caráter histórico, os dados secundários se mostraram de fundamental importância e mereceram, por parte dos autores, cuidadosa análise. Tais dados foram obtidos mediante a busca de boletins internos, de comunicados ao mercado de capitais e de relatórios anuais publicados pela Empresa. Como a LR tornou-se empresa de capital aberto em 1967, o acesso aos relatórios anuais publicados ficou facilitado. Para tanto, foram realizadas buscas nos arquivos da Junta Comercial do Estado do Rio Grande do Sul, no site da Comissão de Valores Mobiliários e nos arquivos da própria Empresa. Foram examinados os relatórios anuais de 34 anos, no período de 1979 a 2012, totalizando um acervo de mais de 400 páginas de documentos. As demonstrações financeiras do mesmo período foram reclassificadas, tabeladas e atualizadas para o ano de 2012, de acordo com a variação do índice nacional de preços ao consumidor (INPC). Também foram examinadas as edições quinzenais da Revista Exame e as anuais da publicação Melhores e Maiores, da Editora Abril, envolvendo o período de 1979 a 2012. Cada vez que alguma matéria reportando-se ao varejo, a empresas varejistas, ou especificamente à LR foi identificada, o referido material foi selecionado, lido e classificado. Buscou-se com o procedimento complementar a coleta de informações e obter visão ampla a respeito do ambiente de negócios, do setor e da empresa. Com esse procedimento, coletaram-se outras 180 páginas de material, as quais também foram analisadas e classificadas.

\begin{tabular}{|c|l|}
\hline ENTREVISTADO & RAZÕES DA SELEÇÃo \\
\hline E1 & $\begin{array}{l}\text { Membro da terceira geração da família que controlou a empresa até 1998. Acompanhou a } \\
\text { trajetória da empresa de maneira mais próxima a partir de 1983. Vivenciou as negociações } \\
\text { envolvendo a venda do controle acionário para a J. C. Penney. }\end{array}$ \\
\hline E2 & $\begin{array}{l}\text { Começou a trabalhar na empresa em 1939. Ocupou os cargos de diretor comercial de 1966 a } \\
\text { 1983, de diretor superintendente de 1983 a 1987 e foi membro do conselho de administração } \\
\text { de 1983 a 1990. Profundo conhecedor da história da empresa. }\end{array}$ \\
\hline E3 & $\begin{array}{l}\text { Executivo com vínculos profissionais com a Empresa desde 1965. Ocupou o cargo de diretor } \\
\text { de 1983 a 2012. Atualmente é membro do conselho de administração. Vivenciou momentos } \\
\text { importantes da história da empresa, tais como as crises dos anos 1980, o reposicionamento, a } \\
\text { recuperação do negócio, a venda do controle acionário e a pulverização do capital. Profundo } \\
\text { conhecedor da história da LR. }\end{array}$ \\
\hline E5 & $\begin{array}{l}\text { Executivo contratado como diretor superintendente em 1991 e que participou ativamente do } \\
\text { processo de reposicionamento e de recuperação da empresa a partir de então. Ainda ocupa o } \\
\text { cargo de principal executivo na organização. }\end{array}$ \\
\hline E6 & $\begin{array}{l}\text { Foi diretor de operações no período compreendido entre 1988 e 1992. Participou do início do } \\
\text { processo de recuperação da empresa a partir de 1991. }\end{array}$ \\
\hline E7 e E8 & $\begin{array}{l}\text { Atual diretora de RH. Foi contratada no início de 1992 e implementou ações coordenadas de } \\
\text { seleção, treinamento e desenvolvimento de pessoal a partir de então. }\end{array}$ \\
\hline E9 & $\begin{array}{l}\text { Funcionárias da empresa nas décadas de 1980 e 1990. Conheceram as operações do centro de } \\
\text { distribuição e o funcionamento das lojas. }\end{array}$ \\
\hline E10 & $\begin{array}{l}\text { Especialista em varejo. Profissional que acompanhou as transformações do setor nas últimas } \\
\text { décadas. Autor de livros sobre varejo. Conhece a empresa e acompanhou as mudanças. }\end{array}$ \\
\hline $\begin{array}{l}\text { Neto do fundador da empresa que vendeu o ponto onde foi instalada a primeira loja da C\&A } \\
\text { em Porto Alegre. Conhece a história relacionada com a instalação do principal concorrente } \\
\text { da LR, na época. }\end{array}$ \\
\hline
\end{tabular}

Figura 1 - Entrevistados e razão da seleção

Fonte: Elaborado pelos autores. 
Para fins de aplicação da técnica de análise de conteúdo, foram criadas, a priori (Bardin, 2009; Franco, 2007), cinco categorias de análise, sendo quatro vinculadas às formas de mobilização de capacidades dinâmicas (Danneels, 2010; Eisenhardt \& Martin, 2000), e uma vinculada às habilidades gerenciais necessárias ao exercício de tais capacidades (Hansen, Perry \& Reese, 2004). A figura 2 apresenta as categorias. À medida que os documentos que amparam a pesquisa foram sendo analisados, as informações resultantes receberam classificação nas respectivas categorias de análise, de acordo com a interpretação dos pesquisadores.
O período central de interesse do estudo vai de 1965, ano em que a LR adquiriu personalidade jurídica própria, a 2012, último ano de coleta de dados. Entretanto, para melhor compreensão da trajetória da Empresa, o relato histórico iniciou-se em 1922. A coleta de dados de diversas fontes de evidência, e a consequente triangulação de informações, contribuiu para garantir a objetividade e a validade da pesquisa. Por fim, para identificar se a interpretação apresentada pelos pesquisadores correspondeu à realidade dos fatos, o relato foi submetido a um especialista-chave, que referendou a apreciação histórica.

\begin{tabular}{|c|l|}
\hline CATEGORIAS & \\
\hline C1 & TÍTULO \\
\hline C2 & Alavancagem dos recursos, capacidades e competências existentes. \\
\hline C3 & Acesso aos recursos, às capacidades e competências externos. \\
\hline C4 & Liberação de recursos, capacidades e competências. \\
\hline C5 & Habilidades gerenciais necessárias ao exercício de capacidades dinâmicas. \\
\hline
\end{tabular}

Figura 2 - Categorias de análise

Fonte: Desenvolvido pelos autores

\section{SUMÁRIO DA HISTÓRIA DA LOJAS RENNER}

A primeira unidade da Lojas Renner (LR) foi aberta em 1922, em prédio alugado, localizado no Centro de Porto Alegre (Pellanda, 1937; Lojas Renner S.A., 2005). Na época, a unidade era um departamento da A. J. Renner \& Cia., um dos maiores grupos industriais do Rio Grande do Sul, e tinha como finalidade distribuir os produtos da fábrica. Em 1932, a LR passou a operar em sede própria, a Renner da Otávio Rocha, como é conhecida pelo público em Porto Alegre. A loja foi ampliada em 1935 e, em 1940, já oferecia um variado mix de produtos, como artigos de moda, utilidades domésticas, artigos de cama, mesa e banho. A experiência acumulada com as vendas a crédito, realizadas desde 1934, permitiu que a LR fosse uma das fundadoras do Serviço de Proteção ao Crédito, em 1955 (Pellanda, 1937).

Em 1958, com o prédio da Otávio Rocha ampliado e modernizado, a loja passou a ocupar 10 pavimentos, contando com inovações, para a época, como a decoração sofisticada e a exposição diferenciada, com manequins que realizavam pequenos movimentos. Outra novidade foi a inauguração do restaurante e casa de chá, além de um setor de cabeleireiro infantil dotado de minicinema. Todas as quartas-feiras, à tarde, havia desfiles de moda no restaurante. Na década de 1960, o mix de produtos foi ampliado com a inclusão de móveis, e iniciou-se o processo de expansão para o interior do Rio Grande do Sul.
Em 1965, a segunda geração da Família Renner assumiu o comando. A segunda metade dos anos 1960 e a década de 1970 foram de prosperidade para a LR. Viagens ao exterior em busca de novidades eram frequentes na época.

Em 1972, a Loja inovou com o lançamento do "Kanto Kente", um departamento diferenciado, destinado à comercialização de moda jovem. O "Kanto Kente" contava com decoração especial, a sua equipe era composta por vendedores jovens e comunicativos, e o ambiente contava com sonorização coerente com o público-alvo. No ano seguinte, houve o lançamento do cartão de crédito próprio, pioneiro no Rio Grande do Sul. As inovações, junto com as campanhas comerciais e premiações oferecidas, contribuíram para que a LR batesse recordes sucessivos de vendas na época.

A década de 1980, caracterizada por taxas de inflação atingindo quatro dígitos anuais e por sucessivos planos econômicos, foi de dificuldades para o varejo como um todo e, em especial, para a LR. A entrada de um forte concorrente internacional em 1976, a C\&A, e as mudanças no ambiente de negócios, com suas sucessivas crises, custaram a ser compreendidas pela gestão da empresa. Com vendas e margens em queda, em 1983 ocorreram modificações nos altos escalões da LR. Chegou ao poder a terceira geração da Família Renner.

A nova administração não conseguiu reverter o quadro financeiro, e a situação agravou-se, ainda mais, a partir de 1987. De 1986 para 1990, a receita líquida da Empresa, em valores de 2012, apresentou 
involução de 67\%. Outros indicadores também apresentaram piora (figura 3). Diante da falta de capital de giro, a LR passou a realizar compras na modalidade condicional e a ceder espaços para terceiros dentro de suas lojas.

\begin{tabular}{|c|c|c|c|c|c|c|c|c|c|}
\hline$\stackrel{0}{Z}$ & 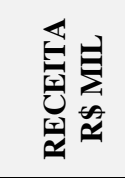 & 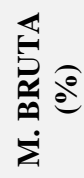 & 空 & 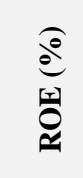 & $\stackrel{0}{Z}$ & 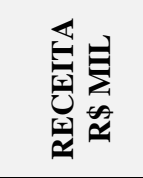 & $\underset{5}{\stackrel{5}{5}}$ & 氛 & 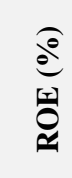 \\
\hline 1986 & 438.038 & 44,8 & 1,12 & 12,9 & 2000 & 1.181 .116 & 43,0 & 1,23 & $-6,5$ \\
\hline 1987 & 322.434 & 11,2 & 1,08 & $-65,4$ & 2001 & 1.199 .194 & 42,7 & 1,24 & $-17,8$ \\
\hline 1988 & 219.959 & 21,3 & 0,83 & 5,6 & 2002 & 1.299 .840 & 43,9 & 1,24 & $-99,1$ \\
\hline 1989 & 233.815 & 36.1 & 1,00 & -3.2 & 2003 & 1.320 .568 & 44,6 & 1,23 & 81,2 \\
\hline 1990 & 145.850 & 40,5 & 0,40 & $-26,0$ & 2004 & 1.440 .394 & 45,7 & 1,27 & 41,9 \\
\hline 1991 & 151.834 & 36,4 & 0,75 & 4,7 & 2005 & 1.633 .734 & 45,6 & 1,41 & 23,8 \\
\hline 1992 & 158.872 & 45,0 & 1,09 & 5,3 & 2006 & 2.141 .064 & 49,0 & 1,17 & 18,4 \\
\hline 1993 & 224.130 & 45,4 & 1,16 & 20,1 & 2007 & 2.567 .577 & 51,2 & 1,11 & 27,0 \\
\hline 1994 & 389.112 & 45,2 & 1,32 & 23,3 & 2008 & 2.726 .561 & 52,0 & 1,20 & 24,4 \\
\hline 1995 & 486.799 & 39,4 & 1,37 & 31,9 & 2009 & 2.834 .989 & 53,0 & 1,20 & 25,0 \\
\hline 1996 & 522.845 & 37,4 & 1,24 & 37,8 & 2010 & 3.099 .574 & 56,0 & 1,63 & 32,6 \\
\hline 1997 & 585.545 & 38,4 & 1,26 & 30,8 & 2011 & 3.439 .433 & 56,9 & 1,53 & 31,0 \\
\hline 1998 & 611.295 & 41,2 & 1,24 & 21,9 & 2012 & 3.862 .508 & 57,6 & 1,18 & 28,9 \\
\hline 1999 & 757.036 & 42,0 & 1,68 & 10,7 & & & & & \\
\hline
\end{tabular}

Figura 3 - Lojas Renner: Evolução dos Indicadores Financeiros (Receita Líquida em valores de 2012) Fonte: Elaborado pelos autores a partir dos Relatórios Anuais publicados pela empresa

A LR manteve, até o final dos anos 1980, o mesmo modo de operação de vendas adotado nos anos 1930, com exposição apenas parcial de produtos e atendimento personalizado. Em 1989, os fornecedores diminuíram os prazos concedidos à $L R$, fato que obrigou a adoção da mesma medida em relação aos clientes. Os reflexos decorrentes foram a redução no nível de vendas e na rentabilidade (figura 3). Ainda mais, o ano de 1990 foi marcado pela introdução do Plano Collor. Naquele momento, a LR estava vivendo uma das piores situações financeiras da sua história.

Diante das dificuldades enfrentadas, a Administração implementou, no final de 1990 e no início de 1991, rigoroso programa de recuperação financeira, envolvendo o fechamento de unidades e a alienação de imóveis, visando a reconstituir o capital de giro. Um amplo programa de redução de despesas, de diminuição do quadro funcional e de otimização de recursos organizacionais foi implementado. Foi feita a escolha de concentrar as atividades em mercados mais promissores, dando preferência à localização de lojas em shoppings. A reformulação iniciada em 1990 teve como ponto de partida a renovação do Conselho de Administração, com a nomeação de empresários com destacada experiência em seus respectivos setores de atuação. $\mathrm{O}$ novo Conselho recomendou a contratação de um consultor para o desenvolvimento do primeiro plano estratégico da LR. Ao final dos trabalhos, o consultor foi convidado a executar o plano, ocupando o cargo de diretor superintendente.
As primeiras ações do novo Superintendente estiveram relacionadas notadamente às questões mercadológicas. A exiguidade de recursos exigiu que o reposicionamento da LR fosse realizado de forma gradual. De acordo com o Diretor Superintendente:

\begin{abstract}
[...] eu estabeleci como prioridade o seguinte: não dá pra fazer tudo ao mesmo tempo. Vamos fazer assim: em 1992 nós vamos acertar o $\mathrm{P}$ de produto e o $\mathrm{P}$ de preço; em 1993 vamos acertar o $P$ ponto-de-venda e em 1994 vamos para o P de promoção. Porque não adianta fazer tudo ao mesmo tempo [...]. Então acertamos os Ps de produto e preço e começou a sobrar algum dinheiro. Com esse dinheiro, começamos o processo de padronização das lojas e quando nós achamos que tínhamos o $\mathrm{P}$ de produto e $\mathrm{P}$ de preço certos, fomos lá, em 1994, e dissemos: venha conhecer a nova Renner! Porque se a gente fosse fazer isso em 1992 seria uma frustração incrível [...].
\end{abstract}

$\mathrm{Na}$ época, uma pesquisa que buscava identificar a opinião dos clientes acerca da LR, apontou que um importante ativo havia permanecido: a marca LR ainda era um ponto forte. Identificou-se, por exemplo, que $24 \%$ do público feminino desejava comprar na LR, mas que apenas $12 \%$ efetivamente comprava, na medida em que não era oferecido o que as clientes esperavam.

A reorganização envolveu, também, profundas modificações na gestão da empresa e em diferentes 
escalões. Novos diretores foram contratados e novas equipes gerenciais foram organizadas. A empresa buscou, no mercado, profissionais de nível gerencial com amplo conhecimento relacionado às atividades de lojas especializadas em moda. Somente a partir do início dos anos 1990, com a contratação de nova gerente de $\mathrm{RH}$, as atividades de desenvolvimento de pessoas foram incrementadas. A evolução das horas médias de treinamento por colaborador, por exemplo, passou de 31 horas, em 1993, para mais de 130 em 2012.

O programa de regionalização da empresa teve início em 1994 com a inauguração de uma loja no Beira Mar Shopping Center, em Florianópolis. Em 1997, a LR começou a direcionar sua expansão para São Paulo. Uma revisão do plano estratégico, realizada em 1996, definiu que a LR deveria atuar em escala nacional, pois só assim conseguiria fazer frente ao seu principal competidor. A expansão, entretanto, exigia recursos financeiros que a Empresa não tinha. Como a captação de recursos bancários não foi aceita pelos acionistas controladores, partiu-se para a busca de um novo sócio, capaz de investir os estimados US\$ 100 milhões necessários. O que iniciou como a busca de sociedade terminou com a venda do controle acionário para a J. C. Penney (JCP), importante varejista americano. Uma variável externa favoreceu o processo de expansão da LR a partir de 1999: a falência das redes Mesbla e Mappin. Esse acontecimento disponibilizou importantes espaços comerciais e acabou facilitando a entrada nos estados da região sudeste e em Brasília. Entre 1998 e 1999, a LR inaugurou 19 lojas, tendo mais do que duplicado sua base instalada que, ao final de 1997, era de 16 unidades.

O período que passou sob o controle acionário da JCP foi de grande aprendizado para a LR. O convívio com a nova controladora durou pouco mais de seis anos. Em 2005, a JCP decidiu vender o controle acionário da LR. O processo de venda do controle ocorreu via mercado de capitais. Uma oferta pública de ações, realizada no segundo semestre de 2005, consolidou a saída da JCP e proporcionou o ingresso de
RS 343 milhões nos cofres da LR. Esses recursos foram determinantes para o segundo grande período de expansão da Empresa.

Importantes ações mercadológicas foram implementadas na primeira década dos anos 2000 como, por exemplo, a exposição dos produtos nas lojas segundo o conceito de estilos de vida (lifestyles) em 2003; o lançamento das minicoleções quinzenais (fast fashion) em 2004; e o início da comercialização de produtos financeiros em 2006. A entrada no mercado nordestino ocorreu em 2006 e na Região Norte em 2007, com a inauguração da loja de Manaus. Entre 2006 e 2012, foram inauguradas 122 unidades, em diversas regiões do país, consolidando um segundo processo de significativa expansão.

No ano de 2010, a LR deu início à abertura de lojas menores, especializadas na comercialização de moda jovem, utilizando, para tanto, o nome da coleção destinada a esse público (Blue Steel). Em 2011, foi adquirido o controle societário da Maxmix Comercial Ltda., empresa com foco em produtos de cama, mesa, banho, utensílios domésticos e artigos de decoração, com 28 lojas em operação no Brasil. Ao final de 2012 havia 188 unidades da LR operando em todas as regiões do Brasil.

\section{ANÁLISE DOS DADOS}

A mobilização de Capacidades Dinâmicas (CD) pode ocorrer por meio da alavancagem dos recursos existentes, da criação e do acesso a novos recursos e também pela liberação de recursos organizacionais (Danneels, 2010; Eisenhardt \& Martin, 2000). A habilidade gerencial de identificar e explorar todo o potencial dos recursos (Hansen, Perry e Reese, 2004) e de realizar uma adequada avaliação dos serviços que os recursos podem prestar (Danneels, 2010) favorecem o exercício de Capacidades Dinâmicas. As análises das entrevistas e dos documentos acessados permitiram identificar tais elementos na LR. A figura 4 apresenta uma síntese da categorização realizada.

\begin{tabular}{|c|l|}
\hline CATEGORIAS & DETALHES \\
\hline $\begin{array}{c}\text { Alavancagem dos } \\
\text { recursos } \\
\text { existentes - C1 }\end{array}$ & $\begin{array}{l}\text { Fábrica como origem dos primeiros recursos; alavancagem mútua (1922 a 1965); Marca Lojas } \\
\text { Renner e lojas da Otávio Rocha e Shopping Iguatemi determinantes no processo de recuperação a } \\
\text { partir de 1991. }\end{array}$ \\
\hline $\begin{array}{c}\text { Gestão do crédito (1934, 1955, 1973, anos 2000), desenvolvimento de coleções, criação de leiautes, } \\
\text { ambiente de loja diferenciado, atendimento personalizado (anos 1960 e 1970), Kanto Kente (1972), } \\
\text { ações de desenvolvimento de RH (a partir de 1991), uso estratégico do conceito de marcas próprias } \\
\text { (a partir de 1991), lançamento de coleções pelo conceito de estilos de vida - lifestyles (2003), } \\
\text { recursos - C2 } \\
\text { desenvolvimento e comercialização de coleções pelo conceito de fast fashion (2004). }\end{array}$ \\
\hline $\begin{array}{c}\text { Acesso a recursos } \\
\text { externos - C3 }\end{array}$ & $\begin{array}{l}\text { Viagens ao exterior nos anos 1960/1970 proporcionando acesso ao conhecimento de ponta no setor; } \\
\text { formação de novo conselho de administração e nova equipe gerencial (1991); relacionamento com a } \\
\text { JCP (1998 a 2005); falência das redes Mappin-Mesbla; IPO (2005). }\end{array}$ \\
\hline $\begin{array}{c}\text { Liberação de } \\
\text { recursos - C4 }\end{array}$ & $\begin{array}{l}\text { Fechamento de unidades no interior (1990); terceirização de atividades não relacionadas ao negócio } \\
\text { principal (1990); venda de imóveis (1990); redução do mix de produtos (1991); redução do quadro } \\
\text { de funcionários (1992); foco em moda, tendo como público-alvo a mulher (1991). }\end{array}$ \\
\hline
\end{tabular}




\begin{tabular}{|c|l|}
\hline $\begin{array}{c}\text { Recomposição da equipe gerencial permitiu que a LR atendesse as condições necessárias à } \\
\text { mobilização de CD; reconquistou a capacidade de interpretar a realidade do ambiente de negócios, } \\
\text { gerenciais - C5 }\end{array}$ & $\begin{array}{l}\text { de identificar a real necessidade dos clientes e de interpretar os serviços que os recursos podem } \\
\text { prestar. }\end{array}$ \\
\hline
\end{tabular}

Figura 4 - Síntese da categorização

Fonte: Elaborado pelos autores.

Procede-se a seguir uma análise de cada um dos mecanismos de mobilização dos recursos.

\subsection{A alavancagem dos ativos}

A mobilização das capacidades dinâmicas, por meio da alavancagem de ativos já possuídos (Categoria 1 - C1), diz respeito ao aproveitamento da base existente de recursos, mediante a sua aplicação em novos usos como, por exemplo, em novas categorias de produtos (Danneels, 2002; 2007; Miller, 2003). Marcas, pontos de venda e outros ativos que evidenciem algum tipo de sinergia tecnológica ou mercadológica são exemplos de recursos que podem ser alavancados.

O início da trajetória da LR foi marcado pela alavancagem dos recursos da Fábrica. Os recursos financeiros para a abertura da primeira unidade (em 1922) e para o processo de expansão que se seguiu, até 1965, quando se tornou independente, além dos principais executivos e dos primeiros estoques, tiveram como origem a empresa-mãe, A. J. Renner \& Cia. Entretanto, mais do que recursos físicos, a Fábrica emprestou à Loja a imagem de uma empresa comprometida com a qualidade dos produtos que oferecia. Essa preocupação marcou a trilha da loja desde a primeira unidade, onde apenas produtos de fabricação própria eram oferecidos. De acordo com o Diretor Superintendente:

\begin{abstract}
A Renner sempre teve muito do Sr. A. J. Renner, do Sr. Pernau, do Sr. Harbich; sempre houve na sua história muita seriedade, preocupação em fazer as coisas certas, preocupação em entregar produtos de qualidade, coisas bem feitas, ineditismo. Tudo isso, praticado durante muitos anos, deixou uma imagem muito positiva da Renner. Nós ratificamos isso em 1992, por meio de uma pesquisa que fizemos.
\end{abstract}

Assim, foi possível constatar que a associação da marca "Lojas Renner" a produtos de qualidade desempenhou papel determinante no processo de recuperação da empresa no começo dos anos 1990. De fato, a marca e a posse de dois importantes pontos-devenda, as lojas da Otávio Rocha e do Shopping Iguatemi, constituíam-se os seus principais ativos, pois a Empresa evidenciava um "feixe de recursos" bastante enfraquecido após uma década de continuidade estratégica. Como declarado pelo Diretor Superintendente, "Eu tinha tudo para fazer e [quase] zero de recursos".
Utilizam-se, para ilustrar e reforçar a argumentação, diversos relatos dos entrevistados.

Associações à marca são relações diretas ou indiretas realizadas na mente dos consumidores, e sua utilização como instrumento de alavancagem de novos negócios depende dessa vinculação. Assim, as associações à marca podem tanto favorecer quanto inibir a geração de inovações ou de novos negócios (Meyvis \& Janiszewski, 2004). A vinculação de uma marca com atributos mais abstratos, como, por exemplo, estilo, favorece o seu uso estendido, enquanto vinculações a classes de atributos mais concretos, tais como o sabor de uma pasta de dente ou de uma cerveja, tornam a sua extensão mais difícil. $\mathrm{O}$ uso estendido de uma marca também se torna mais fácil quando os consumidores carregam em sua memória imagens positivas acerca de uma marca original ou quando há um nível mínimo de ajustamento entre as diferentes classes de produtos nos quais, eventualmente, ela esteja sendo empregada (Aaker \& Keller, 1990). Já a vinculação referente a categorias de produtos, por sua vez, pode impedir a extensão de uma marca forte para outras categorias (Danneels, 2010).

A percepção da LR comercializando produtos de qualidade e de glamour, construída ao longo dos anos 1960 e 1970, ainda permanecia na mente dos consumidores no início dos anos 1990. De fato, a marca, anteriormente associada à moda masculina e a comercialização de um amplo mix de produtos, contribuiu, a partir de 1990, para o reposicionamento da LR enfocando mais especificamente a mulher. O fato de quase $25 \%$ das mulheres ainda manifestarem, numa pesquisa realizada, o desejo de comprar na LR, mostra a forte vinculação das consumidoras com a marca.

\subsection{A criação de novos recursos e capacidades}

Por sua vez, a criação de novos recursos diz respeito ao desenvolvimento de rotinas pelas quais os gerentes criam novas formas de agir e de pensar dentro da empresa (Categoria 2 - C2). O acesso a novos recursos externos, pela da realização de alianças, por exemplo, também pode favorecer a renovação do conhecimento organizacional e, a partir daí, instigar a criação interna de recursos (Eisenhardt \& Martin, 2000).

O aprendizado desenvolvido internamente, relacionado com as atividades de análise e concessão de crédito é um dos fatos que evidencia a capacidade da LR de criar, internamente, recursos, capacidades e 
competências importantes para o sucesso do negócio. Os processos organizacionais relacionados à gestão do crédito, desenvolvidos desde 1934, que a colocaram como uma das fundadoras do Serviço de Proteção ao Crédito, resultaram no desenvolvimento de rotinas específicas e na organização de uma base de dados própria. Mais adiante, em 1973, os conhecimentos relacionados a essa atividade permitiram que a LR fosse pioneira no lançamento do cartão de crédito próprio no RS, instrumento que não só agilizou suas operações, mas que também serviu como meio de fidelização da base de clientes.

O conhecimento acumulado nessa atividade, ao longo da trajetória organizacional, foi mais uma vez aproveitado em 2005, quando a empresa deu início à comercialização de produtos financeiros, e em 2007, quando a sua oferta foi ampliada, mediante a inclusão de produtos como empréstimos pessoais e seguros. Em 2011, a LR passou a emitir cartões de crédito em conjunto com as empresas MasterCard e Visa, denominados de cartões co-branded, tornando-se a primeira instituição não financeira do mundo a ser certificada simultaneamente pelas referidas operadoras.

Durante as décadas de 1960 e 1970, a empresa construiu uma imagem de glamour em torno da marca LR, por meio de ações, tais como as viagens realizadas ao exterior pela equipe gerencial, contratação de consultores de moda, a tradução de revistas internacionais especializadas em moda e a realização de encontros visando à difusão do conhecimento entre os gerentes das diferentes unidades. Essas ações favoreceram o desenvolvimento e a ampliação de competências relacionadas ao desenvolvimento de coleções, à exposição de produtos, à forma de atendimento (personalizado), à criação de leiautes e à realização de eventos promocionais, como os já relatados tradicionais desfiles de moda realizados às quartas-feiras à tarde.

Em 1972, o lançamento do Kanto Kente, um espaço da loja dedicado à comercialização de moda jovem, revelou a capacidade da empresa em identificar novas oportunidades e em conciliar, tanto internamente, quanto diante de seus clientes, o tradicional com o irreverente. A ambientação, os produtos, os fornecedores, os profissionais encarregados de identificar tendências e realizar as compras, os clientes, a sua forma de atendimento e a comunicação do Kanto Kente eram bastante diferentes dos praticados nos demais departamentos da Loja. A aceitação da proposta pelo público jovem revelou a capacidade não de apenas criar a novidade, mas também de operacionalizá-la e de comunicá-la adequadamente ao mercado alvo.

Os documentos acessados e as entrevistas realizadas permitiram identificar que os anos 1980 foram de continuidade estratégica para a LR. Por mais de dez anos a Empresa apresentou um comportamento mais voltado ao aproveitamento da base existente de recursos (exploitation) do que à busca de sua renovação (exploration). Exceção feita à abertura da unidade do
Shopping Iguatemi (em 1983), não se identificaram outros procedimentos relacionados com a criação de novos recursos, capacidades e competências entre 1980 e 1991. A declaração de um dos diretores evidencia o processo de desajustamento pelo qual a LR passou no período em questão.

[...] as pessoas queriam comprar na Renner, mas não podiam mais comprar na Renner, porque elas queriam pagar vinte e a Renner estava vendendo por vinte e seis. Ela não se adequou à nova realidade da sociedade brasileira, que vivia outra situação. Acabou o milagre, voltamos a ser brasileiros normais. Por não ver essa realidade, a Renner passou a ter dificuldades, passou a ter quedas de vendas, enfim, passou por todas essas dificuldades. Aí, mil e uma coisas foram tentadas. E como começou a faltar capital de giro, ela começou a alugar espaços dentro da loja. Foi cada vez mais se descaracterizando. A Renner chegou a vender mel, sabe o que é isso, vender mel! Então se alugavam espaços para grifes, para lojas de tênis. A Renner quase ficou como um minisshopping. Então, imagina todo aquele glamour, todo aquele posicionamento, e as pessoas, os clientes observando essas coisas todas. Era uma tentativa de fazer renda e receber um percentual, porque não tinha capital de giro para fazer as compras.

O ano de 1991 marcou o início de um novo período de aprendizado capaz de favorecer a recomposição da base de recursos, capacidades e competências da LR. Além da renovação gerencial, diversas ações da área de recursos humanos foram identificadas, merecendo destaque, dentre outros, os programas de "Desenvolvimento de Trainees" (1992), o programa "Escalada 2001" (1997), que visava preparar os executivos de nível gerencial para as mudanças que a empresa enfrentaria nos próximos anos, o "MBA em Varejo" (2002) destinado aos profissionais de nível executivo, o lançamento do "Programa de Sucessão" (2006) visando a identificação de talentos e o planejamento da sucessão em cargos de destaque e o programa "Liderança Executiva" (2008), destinado ao desenvolvimento de novos líderes.

Além da marca tradicional da LR e o reposicionamento em relação ao público feminino, a partir da primeira metade dos anos 1990, a LR começou a construir suas próprias competências relacionadas à utilização estratégica do conceito de marcas próprias. Assim, o conceito de marcas próprias, cerne da estratégia da C\&A, também foi desenvolvido na LR. Por trás desse conceito, havia mais do que apenas uma estratégia comercial. Tratavase de uma ação importante para a consolidação do reposicionamento da empresa tanto em relação aos clientes quanto aos fornecedores. A adoção do conceito contribuiu, juntamente com a redefinição do mix de 
produtos, para que a margem bruta de lucro da LR passasse a apresentar evolução a partir de 1992.

O conceito de estilos de vida (lifestyles) começou a ser adotado na primeira metade da década de 2000, quando a LR realizou nova alteração no leiaute de suas lojas e deixou de efetuar a exposição dos produtos por categorias, passando a realizá-la segundo diferentes lifestyles. As lojas foram, então, segmentadas em espaços específicos, destinados à exposição de coleções orientadas segundo o novo conceito. As coleções, os volumes específicos de compras e as lojas para as quais as mesmas se destinavam passaram a ser definidos por uma equipe envolvendo os gerentes de produto, de planejamento e de estilo. O procedimento não é considerado, pela administração da LR, como uma mera exposição diferenciada de produtos, pois envolve a coordenação de diferentes capacidades funcionais, desde aquelas vinculadas à identificação e ao desenvolvimento do lifestyle até as relacionadas à comunicação, à exposição e à venda das mercadorias. Sob o enfoque de resultados, o conceito incentiva a compra por impulso, favorece o aumento de vendas cruzadas e contribui para a redução da necessidade de realização de liquidações, refletindo-se, portanto, de forma positiva, na margem bruta de vendas.

Outro evento que sinalizou a recuperação da capacidade de renovar e criar recursos, capacidades e competências na LR, foi a introdução do conceito de minicoleções quinzenais (fast fashion), em 2004. A renovação rápida de modelos com maior apelo de moda, estratégia originalmente aplicada por pequenos comerciantes de Barcelona (Martínez, 2012) e ajustada para operações com escala maior, pela espanhola Zara, no início dos anos 1990 (Álvarez Blanco, 2006; Ghemawat \& Nueno, 2003), tem como objetivo provocar a sensação de escassez do produto e incentivar a compra por impulso. Os benefícios decorrentes, para as lojas, são o aumento do giro dos estoques, a rápida identificação de modelos de maior aceitação e a melhoria da margem, visto que os modelos não aprovados pelos consumidores são rapidamente identificados e têm sua encomenda e compra suspensos, evitando-se o acúmulo de estoques e a necessidade da realização de promoções. A operacionalização do conceito de fast fashion exigiu da LR a adequada comunicação e a integração entre as equipes de desenvolvimento, compras, fornecedores, logística, exposição e vendas. Exigiu, também, o emprego de tecnologias que facilitassem e agilizassem o desenvolvimento das atividades decorrentes, tanto internas, quanto externas, com seus fornecedores.

\subsection{0 acesso a recursos externos}

A terceira categoria de análise, diz respeito ao acesso a recursos externos (Categoria 3 - C3). O referido acesso pode ser efetivado por meio de aquisições e da realização de alianças com outras empresas (Eisenhardt \& Martin, 2000). Pode, também, ser realizado através de relacionamentos da empresa e de seus gestores com outros empresários e executivos, por meio do relacionamento com outras empresas do grupo, com consultores, com membros do conselho de administração, com fornecedores, ou, ainda, pela da contratação de profissionais da concorrência.

Os relacionamentos estabelecidos pela Fábrica abriram portas para que os executivos da LR visitassem empresas no exterior. $\mathrm{O}$ acesso ao conhecimento advindo do exterior, cuja difusão era bem mais lenta na época, favoreceu o desenvolvimento e a renovação dos recursos e competências da LR nos anos 1960 e 1970, notadamente àqueles relacionados à identificação de tendências e ao desenvolvimento e lançamento de coleções.

Já os anos 1980 foram marcados significativamente pelo aproveitamento dos recursos desenvolvidos no passado (exploitation), fato que conduziu ao agravamento da situação financeira da Empresa. Foi então que, como destacado no primeiro parágrafo do Relatório da Administração de 1992, "A Renner decidiu mudar". Essa mudança teve como elemento seminal a formação de novo Conselho de Administração (1991). As contribuições apresentadas por esse Conselho foram decisivas para o processo de renovação da LR. Na opinião de um membro da Família Renner "A formação desse grupo [de conselheiros] foi fundamental para a recuperação da empresa. Este grupo [...] formado por pessoas de sucesso [...], empresários e executivos de destaque [...] realmente deu uma direção clara [para o negócio]".

A venda do controle acionário para a JCP em 1998, por sua vez, proporcionou o acesso aos recursos financeiros que a LR necessitava para materializar o seu processo de expansão. Foi o contrato de mútuo firmado com o novo controlador, em 1999, no valor de US\$ 80 milhões, que permitiu a contratação de pontosde-venda e a equipagem das lojas, no primeiro processo de grande crescimento verificado a partir de então. Entretanto, de acordo com dois diretores, o relacionamento com a JCP proporcionou mais do que recursos financeiros: trouxe benefícios em termos de capacidades relacionadas a auditorias, controles e gestão de estoques e do relacionamento com fornecedores. $\mathrm{O}$ depoimento de um conhecido consultor do segmento varejista amplia e enfatiza os benefícios decorrentes do relacionamento com a JCP:

[...] a aquisição pela JCP trouxe conceitos internacionais, descortinou as melhores práticas de gestão do varejo dos EUA e a LR pôde absorver tudo isso numa velocidade muito grande, não por livro ou por visita, mas como insider, pois recebeu toda esta injeção de competência, de informação, de práticas, benchmarks, diretamente na veia. E quando a JCP saiu deixou como legado um modelo de gestão, de profissionalização, uma estrutura equivalente a de uma grande corporação do varejo de moda global [...]. 
Já a materialização da ampliação do escopo geográfico da LR, decidido em 1996, por ocasião da revisão do plano estratégico elaborado em 1991, dependia da disponibilidade de pontos-de-venda bem localizados na região sudeste do Brasil, o novo mercado alvo da Empresa. O acesso a tal mercado foi favorecido pela incidência de uma variável externa: a falência das redes Mesbla e Mappin em 1999. Esse acontecimento disponibilizou importantes espaços comerciais e acabou facilitando a entrada nos estados da região sudeste e em Brasília. Entre 1998 e 1999, a LR inaugurou 19 lojas, tendo mais do que duplicado sua base instalada. De acordo com o Diretor Superintendente, a saída das redes Mesbla e Mappin "[...] foi uma grande oportunidade para a Renner se expandir! [...] foi aí realmente o grande momento da Renner, [...] de repente a gente se transformou numa empresa nacional".

Se a aquisição do controle acionário pela JCP (em 1998) contribuiu para que a LR acessasse recursos estratégicos importantes ao seu processo de renovação e crescimento, com a venda do controle acionário, ocorrida em 2005, não foi diferente. O processo de venda do controle, via mercado de capitais, proporcionou o ingresso líquido de $\mathrm{R} \$ 343$ milhões nos cofres da LR. Foi o acesso a esse importante recurso financeiro que proporcionou o segundo momento de grande expansão da LR.

\subsection{A liberação de recursos}

Outra forma de mobilização de capacidades dinâmicas, identificada por Eisenhardt e Martin (2000), também foi utilizada pela nova administração da LR para sustentar parte do processo de renovação da base de ativos da Empresa: a desmobilização e a liberação de recursos (Categoria 4 - C4). O fechamento de unidades em 1990 no interior do Rio Grande do Sul, a terceirização de atividades não relacionadas ao negócio principal (transporte, segurança, limpeza e alimentação, por exemplo), a venda e a realização da operação de sale and leaseback de diversos imóveis forneceram parte dos recursos financeiros que tornaram possível o início da reconfiguração dos recursos da Empresa. O quadro de funcionários, por exemplo, que em 1987 era de 1.960 colaboradores, reduziu-se para apenas $824 \mathrm{em}$ 1992.

A concentração das atividades numa linha mais reduzida e as mudanças introduzidas na forma de atendimento e de exposição de produtos também ocasionaram a liberação de recursos. Durante muitos anos a LR ficou conhecida como uma loja de departamentos que oferecia amplo mix de produtos. Para tanto, precisava saber como gerenciar operações relacionadas a compras, a movimentação, exposição e venda dos mais diferentes produtos, de calçados a refrigeradores. Ao decidir-se pela redução do mix, focando exclusivamente na linha mole (vestuário, calçados, cama, mesa e banho), as habilidades relacionadas à ampla linha foram liberadas e os ativos empregados no seu desempenho receberam novas aplicações.

\subsection{Habilidades gerenciais e capacidades dinâmicas}

A última categoria de análise reporta-se às habilidades gerenciais e ao exercício de capacidades dinâmicas (Categoria 5 - C5). A partir de 1976, com a entrada da C\&A no Brasil, e mais notadamente a partir do início dos anos 1980, quando o ambiente econômico piorou, a LR foi desafiada a mobilizar capacidades dinâmicas. A base de recursos que a havia conduzido à condição de lançadora de moda e proporcionado uma imagem de glamour em torno da sua marca, não era mais suficiente à boa condução dos negócios.

Assim, constatou-se, a partir dos documentos e dos depoimentos, que a LR deixou de mobilizar capacidades dinâmicas a partir do momento em que se tornou obscura, para a sua gestão, a compreensão da nova realidade do ambiente de negócios, das reais necessidades e dos desejos dos clientes e dos verdadeiros serviços que os seus recursos organizacionais podiam oferecer. A figura 5 sintetiza questões relacionadas às habilidades gerenciais e o exercício de capacidades dinâmicas.

\begin{tabular}{|l|l|}
\hline \multicolumn{1}{|c|}{ CONDIÇÃO NÃO ATENDIDA } & \multicolumn{1}{|c|}{ CONSTATAÇÃO EMPÍRICA } \\
\hline $\begin{array}{l}\text { Perdeu a capacidade de interpretar a } \\
\text { realidade do ambiente de negócios. }\end{array}$ & $\begin{array}{l}\text { Novo entrante alterou significativamente as regras do jogo, a realidade } \\
\text { econômica mudou com a introdução de medidas restritivas ao consumo, } \\
\text { congelamento de preços e salários, e a LR custou a perceber a nova realidade. }\end{array}$ \\
\hline $\begin{array}{l}\text { Perdeu a capacidade de identificar as reais } \\
\text { necessidades dos clientes. }\end{array}$ & $\begin{array}{l}\text { As pessoas queriam comprar na LR, mas a LR não tinha o que as pessoas } \\
\text { queriam. As pessoas podiam pagar \$ 20, mas a LR estava vendendo por \$26. }\end{array}$ \\
\hline $\begin{array}{l}\text { Perdeu a capacidade de identificar e en } \\
\text { interpretar os recursos e os serviços que os } \\
\text { recursos poderiam oferecer. }\end{array}$ & $\begin{array}{l}\text { Continuou usando a sua base de recursos do mesmo modo. Terceirizou } \\
\text { espaços dentro das lojas e passou a oferecer um mix de produtos incoerente } \\
\text { com os pontos de venda e a tradição da empresa. }\end{array}$ \\
\hline
\end{tabular}

Figura 5 - Habilidades gerenciais e o exercício de CD

Fonte: Elaborado pelos autores. 
A forma e a extensão pela qual as capacidades dinâmicas são exercidas dependem do conhecimento, por parte dos executivos em posição de decisão, dos recursos empresariais e da correta percepção sobre os serviços que estes podem prestar em diferentes situações. Argumenta-se, adicionalmente, que, se a essência da estratégia é vincular a empresa e o seu ambiente (Porter, 1986), então a mobilização de capacidades dinâmicas também exige dos gerentes a habilidade de adequadamente interpretar novas realidades do ambiente de negócios e das necessidades dos clientes. É a partir destes três elementos, (1) adequada leitura do ambiente de negócios, (2) das necessidades dos clientes e (3) da identificação do valor dos recursos e dos serviços que eles podem prestar em diferentes situações, que possíveis trajetórias futuras se tornam mais claras para as empresas.
A renovação gerencial, realizada a partir de 1991, permitiu que a LR voltasse a atender as condições necessárias à mobilização de capacidades dinâmicas. A nova gestão identificou o que necessitava ser feito, avaliou a base de recursos possuídos, identificou possíveis novos usos aos dois principais recursos ainda possuídos (marca e pontos-de-venda) e buscou acessar e criar outros, além de liberar àqueles recursos não mais necessários diante da nova realidade. Se há uma distinção a ser feita entre recursos e os serviços que eles podem proporcionar (Penrose, 2006), há, também, uma distinção entre os serviços que os recursos podem prestar e o que os gerentes pensam que eles podem proporcionar (Danneels, 2010).

As evidências empíricas relatadas nos parágrafos anteriores são apresentadas de forma consolidada na figura 6 , destacando-se, em conjunto, numa linha do tempo (eixo das abscissas), a evolução do número de lojas (eixo das ordenadas).

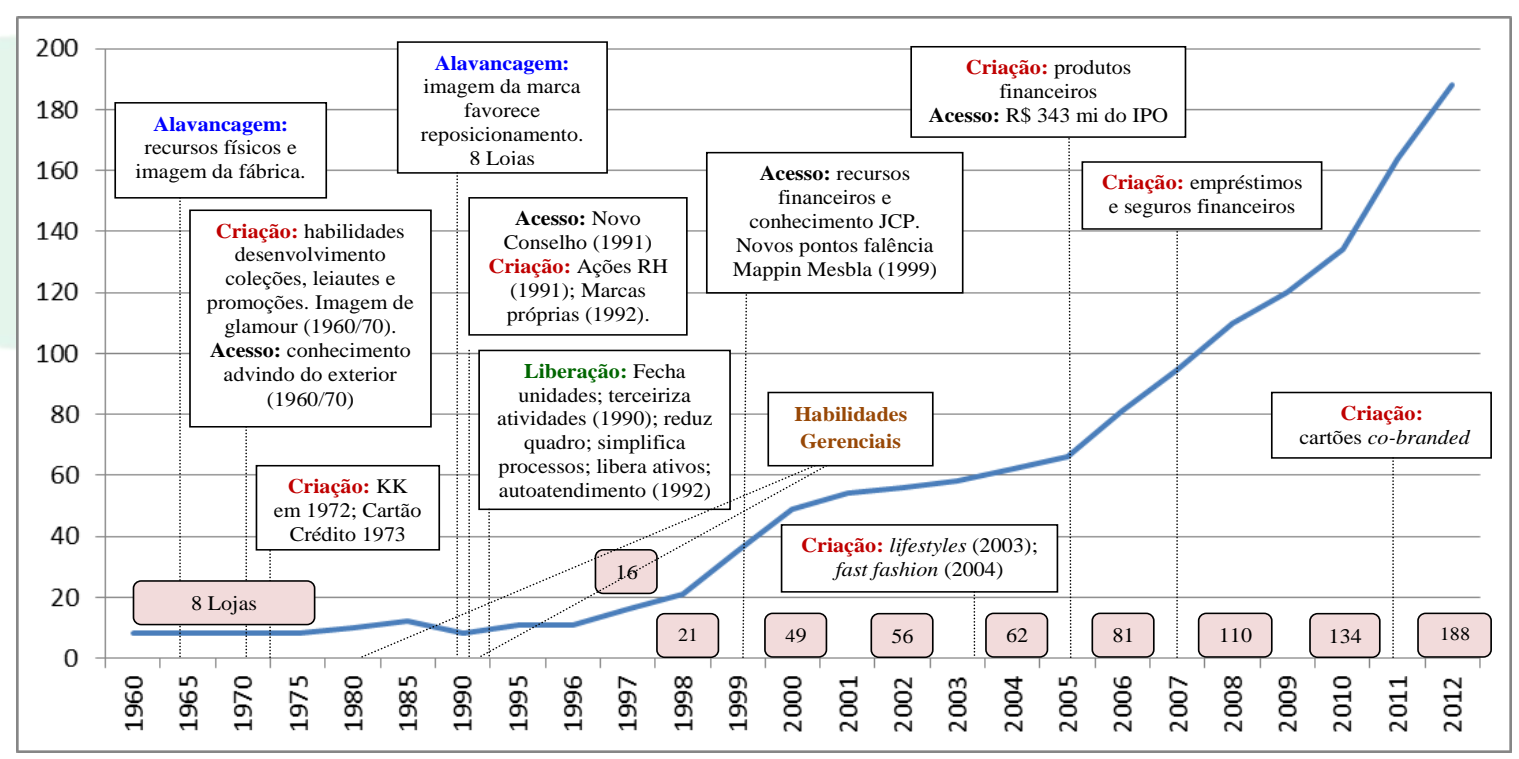

Figura 6 - Síntese das evidências empíricas

Fonte: Elaborado pelos autores.

As diferentes formas de mobilização das capacidades dinâmicas por parte da LR também podem ser organizadas e apresentadas tendo como base contextos e condições específicas do ambiente de negócios. A figura 7 separa o período analisado em quatro grandes blocos, norteados por condições ambientais e características gerais do setor de atuação. A partir de tal caracterização, sintetiza a realidade específica da empresa e destaca as diferentes formas de mobilização de capacidades dinâmicas identificadas pela pesquisa.

A separação do período analisado, considerando as condições específicas do ambiente de negócios, não permitiu atribuir importância maior a uma categoria específica de mobilização de capacidades dinâmicas, em razão da existência de contextos competitivos diferenciados. As quatro formas identificadas por Eisenhardt \& Martin (2000) revelaram-se importantes nos diferentes momentos estudados. Entretanto, alguns comentários tornam-se necessários quanto às categorias C2 - Criação de novos recursos e capacidades e C4 - Desmobilização e liberação de recursos.

A criação de novos recursos e capacidades (Categoria $2-\mathrm{C} 2$ ), teve sua dinâmica acentuada na década de 2000, em função das escolhas realizadas pela empresa e da existência de um contexto competitivo ainda mais dinâmico. A dinâmica do ambiente de 
negócios durante os anos 1960 e 1970 imprimia velocidade menor à habilidade organizacional em trabalhar leiautes de loja e desenvolver coleções. Na época, os ambientes de loja mudavam com menor rapidez, fruto da menor velocidade com que as inovações, normalmente oriundas do exterior, eram acessadas. Já o desenvolvimento de coleções preocupava-se com o desenvolvimento de uma única coleção para cada estação do ano, fato alterado significativamente com o advento do conceito de fast fashion, introduzido no país, no final dos anos 1990, pela rede espanhola Zara. Este conceito trabalha com o desenvolvimento de minicoleções a cada quinzena, exigindo criatividade, comunicação e integração entre as equipes envolvidas. Assim, a velocidade atual das exigências é bastante diferente daquela identificada durante a década de 1960 e 1970, quando o desenvolvimento de uma única coleção atendia a demanda de toda a estação.

\begin{tabular}{|c|c|c|c|c|}
\hline DETALHES / ANOS & $1960 / 1970$ & 1980 & 1990 & 2000 \\
\hline $\begin{array}{l}\text { Crescimento médio } \\
\text { anual PIB }\end{array}$ & $7,5 \%$ & $1,7 \%$ & $2,7 \%$ & $3,7 \%$ \\
\hline Inflação IGP-FGV & $\begin{array}{c}\text { Eleva-se a partir de } \\
\text { 1976. Atinge a casa } \\
\text { dos três dígitos em } \\
\text { 1980. Média anual } \\
\text { 43,1\%. }\end{array}$ & $\begin{array}{c}\text { Descontrole } \\
\text { inflacionário. Atinge } \\
\text { a casa dos quatro } \\
\text { dígitos em 1988. } \\
\text { Média anual 564,3\% }\end{array}$ & $\begin{array}{c}\text { Elevada nos quatro } \\
\text { primeiros anos. Sob } \\
\text { controle a partir de } \\
\text { 1994. Média anual } \\
\text { após } 199410,0 \%\end{array}$ & $\begin{array}{c}\text { Sob controle. Média } \\
\text { anual } 8,9 \%\end{array}$ \\
\hline Setor & $\begin{array}{c}\text { Medidas econômicas } \\
\text { produzem efeitos } \\
\text { positivos a partir de } \\
\text { 1968. Vendas em } \\
\text { elevação (1968 - } \\
\text { 1973). Setor } \\
\text { caracterizado pela } \\
\text { atuação regional. } \\
\text { Poucas empresas } \\
\text { com atuação } \\
\text { nacional. }\end{array}$ & $\begin{array}{l}\text { Planos econômicos } \\
\text { afetam preços } \\
\text { relativos, poder } \\
\text { aquisitivo e vendas do } \\
\text { setor. Breves períodos } \\
\text { de recuperação em } \\
1984 \text { e } 1986 . \\
\text { Aumenta a } \\
\text { competição. }\end{array}$ & $\begin{array}{l}\text { Quebra de grandes } \\
\text { redes. Plano Real } \\
\text { afeta positivamente } \\
\text { vendas do setor de } \\
\text { 1994 a 1996. Crises } \\
\text { de } 1997 \text { e } 1998 \\
\text { trazem estagnação e } \\
\text { queda de vendas. }\end{array}$ & $\begin{array}{l}\text { Aumento do emprego } \\
\text { e renda, notadamente } \\
\text { a partir de 2003, com } \\
\text { reflexos positivos no } \\
\text { setor. Período de } \\
\text { significativo } \\
\text { crescimento das } \\
\text { grandes redes. }\end{array}$ \\
\hline Empresa & $\begin{array}{c}\text { Destacadas } \\
\text { habilidades no } \\
\text { desenvolvimento de } \\
\text { coleções, de leiautes } \\
\text { e realização de } \\
\text { promoções. Imagem } \\
\text { de Glamour, de } \\
\text { lançadora de moda. }\end{array}$ & $\begin{array}{l}\text { Período caracterizado } \\
\text { pela continuidade } \\
\text { estratégica. Base de } \\
\text { recursos sem } \\
\text { renovação expressiva. }\end{array}$ & $\begin{array}{l}\text { “A Renner decidiu } \\
\text { mudar!” } \\
\text { Remobilização. } \\
\text { Renovação do C. de } \\
\text { Administração. } \\
\text { Grande recomposição } \\
\text { da base de recursos. }\end{array}$ & $\begin{array}{l}\text { Período de grande } \\
\text { crescimento. } \\
\text { Renovação constante } \\
\text { da base de recursos. }\end{array}$ \\
\hline $\begin{array}{l}\text { Mobilização de } \\
\text { Capacidades } \\
\text { Dinâmicas }\end{array}$ & $\begin{array}{c}\text { Alavancagem } \\
\text { Criação } \\
\text { Acesso }\end{array}$ & Não identificada & $\begin{array}{c}\text { Alavancagem } \\
\text { Acesso } \\
\text { Criação } \\
\text { Liberação }\end{array}$ & $\begin{array}{c}\text { Alavancagem } \\
\text { Criação } \\
\text { Acesso }\end{array}$ \\
\hline
\end{tabular}

Figura 7 - A mobilização de capacidades dinâmicas em diferentes contextos competitivos Fonte: Elaborado pelos autores.

Por fim, constatou-se que a desmobilização e a liberação de recursos (Categoria 4 - C4) ganhou relevância no início dos anos 1990, em razão das peculiaridades do momento organizacional vivenciado pela LR na época. Em outras palavras, a dimensão das mudanças organizacionais necessárias, no início dos anos 1990, tornou imperativo não apenas acessar, alavancar e criar novos recursos, mas também decidir sobre a liberação de recursos, importantes no passado, mas que não se ajustavam mais às demandas do ambiente de negócios e às escolhas realizadas pela Empresa na época. O longo período de continuidade estratégica verificado nos anos 1980, por certo tornou mais grave a referida liberação de recursos, que teria se revelado menos traumática, caso o ajustamento tivesse ocorrido de modo gradual. 


\section{CONSIDERAÇÕES FINAIS}

O estudo das Lojas Renner focado ao longo dos seus 90 anos, e, particularmente, durante as quatro últimas décadas, se revela de importância para o entendimento da forma como uma empresa líder em seu setor segue uma trajetória de crises, superações, de recuos e de avanços. Ao longo da pesquisa, optou-se por considerar como a empresa mobilizou seus recursos e como foi capaz de estabelecer-se em praticamente todo o território nacional, acrescendo constantes fatias do mercado. Assim, a pesquisa realizada possibilitou reflexões teóricas e algumas lições para a prática gerencial.

Com relação às contribuições teóricas, as categorias de mobilização de recursos discutidas - a alavancagem; a criação de novos recursos; o acesso e a liberação de recursos e capacidades (Danneels, 2010; Eisenhardt \& Martin, 2000) - mostraram-se adequadas para estudos longitudinais. Essas categorias possibilitaram a identificação e a caracterização dos momentos em que a empresa mobilizou suas capacidades dinâmicas e os resultados provenientes dessa mobilização.

Observou-se que o setor ao qual pertence a empresa objeto do estudo, apesar de apresentar mudanças e testar a capacidade de criação e de adaptação das empresas que dele fazem parte, pode ser considerado como de dinâmica moderada. Efetivamente, o mesmo não apresenta a velocidade de mudança observada em setores de dinamismo acentuado, onde novas tecnologias, padrões e produtos surgem com frequência, tornando obsoletos os anteriores, como é o caso do setor de tecnologia da informação. Mostrou-se, por meio deste estudo, que, mesmo em setores com menor taxa de mudança ambiental, é possível identificarem-se crises e oportunidades que incentivam a mobilização das capacidades dinâmicas. Assim, fugindo das críticas sobre a tautologia inerentes, o conceito de capacidades dinâmicas se manifesta como importante para o estudo das transformações organizacionais ao longo do tempo. Com relação às implicações gerenciais, este estudo mostrou que determinadas habilidades dos

\section{REFERÊNCIAS}

Aaker, D. A., \& Keller, K. L. (1990) Consumer evaluations of brand extensions. Journal of Marketing, 54, 27-41.

Álvarez, J. S., \& Blanco, X. R. (2006) Amancio Ortega: de zero a Zara. Esfera. Lisboa.

Ansoff, I. (1977) Estratégia empresarial. (A. Z. Sanvicente, Trad.). São Paulo. McGraw-Hill.

Arruda, C., Brasil, H. V., Santana, J. L., Campana, R., Santos, R. C. F. M., Nogueira, D. N. (2007) gestores se mostram essenciais na trajetória de uma empresa. A base de recursos organizacionais constituise num elemento necessário à conquista de vantagem competitiva, porém não suficiente, notadamente em ambientes onde a mudança, em maior ou menor escala, é a tônica. Diante de tal realidade a ênfase está na habilidade gerencial em reorganizar, de modo coerente, a sua base de recursos, liberando ou alavancando recursos já existentes, criando ou, ainda, acessando novos recursos. De pouco adiantam recursos valiosos, raros, difíceis de imitar e de substituir, se a equipe gerencial não sabe como aplicar e obter melhor desempenho de tais ativos.

Entre as habilidades gerenciais, é possível destacar, ainda, a capacidade de leitura adequada do ambiente de negócios, de compreensão das necessidades dos clientes e de entender o nível de fungibilidade dos recursos e os diferentes serviços que podem proporcionar. Embora as duas primeiras estejam presentes em grande parte da literatura prescritiva em Administração, a questão da análise da fungibilidade dos recursos e dos serviços que podem prestar aparece em menor grau. Argumenta-se aqui que descartar recursos, capacidades e ativos, é, também, uma habilidade gerencial que pode representar um diferencial competitivo para a empresa. Descartar recursos não significa abandoná-los, mas, sim, trocálos, substituí-los ou vendê-los.

Este artigo não está isento de limites. Ao contrário, apresenta, por exemplo, as tradicionais limitações de um estudo de caso único. As pesquisas dessa natureza abordam de forma mais completa as complexidades de uma situação individual, mas podem pecar por perder a visão do todo. Embora tenham sido adotados procedimentos metodológicos para garantir a possibilidade de replicação, a validade e a fidedignidade do estudo, a impossibilidade de se realizar inferências a outras organizações permanece. A realização de outros estudos de mesma natureza, notadamente envolvendo a análise de múltiplos casos contribuirá para a consolidação das constatações aqui apresentadas. Nesse sentido, espera-se que este artigo possa servir de motivador para pesquisas futuras.

Empresas duradouras, (Relatório de Pesquisa), Nova Lima, MG, FDC.

Bardin, L. (2009) Análise de conteúdo (L. A. Reto \& A. Pinheiro, Trad.) Lisboa. Edições 70.

Barney, J. B. (1991) Firm resources and sustained competitive advantage. Journal of Management, 17 (1), 99-120.

Danneels, E. (2002) The dynamics of product innovation and firm competences. Strategic Management Journal, 23, 1059-1121. 
Danneels, E. (2007) The process of technology competence leveraging. Strategic Management Journal, 28, 511-533.

Danneels, E. (2010) Trying to become a different type of company: Dynamic capability at Smith Corona. Strategic Management Journal, 32, 1-31.

Editora Abril (1979 a 2012) Revista Exame: melhores \& maiores. São Paulo, SP.

Eisenhardt, K.; \& Martin, J. (2000) Dynamic capabilities: What are they? Strategic Management Journal, 21, 1105-1121.

Franco, M. L. P. B. (2007) Análise de conteúdo. Brasília, DF. Líber Livro.

Ghemawat, P., Nueno, J. L. (2003) Zara: Fast fashion. Casos Harvard.

Hansen, M. H., Perry, L. T., Reese, C. S. (2004) A bayesian operationalization of the resource-based View. Strategic Management Journal, 25, 12791295.

Helfat, C. E., Finkelstein, S., Mitchell, W., Peteraf, M. A., Singh, H., Teece, D. J., Winter, S. G. (2007) Dynamic capabilities: understanding strategic change in organizations. Oxford: Blackwell Publishing.

Helfat, C. E., Peteraf, M. A. (2009) Understanding dynamic capabilities: progress along a developmental path. Strategic Organization, 7 (1), 91-102.

Kraatz, M. S., \& Zajac, E. J. (2001) How organizational resources affect strategic change and performance in turbulent environments: theory and evidence. Organization Science, 12 (5), 632-657.

Lojas Renner S.A. (1966 a 2012) Relatórios anuais publicados.

March, J.G. (1991) Exploration and exploitation in organizational learning. Organization Science, 2, 71-87.

Martínez, D. (2012) Zara: visión y estrategia de Amancio Ortega. Conecta.

Martins, T. S., Kato, H. T., Martins, R. R. R., Damião, E. S., Cruz, J. A. W. (2013) Escolhas estratégicas e capacidades dinâmicas na hotelaria. Encontro da Anpad, 37. RJ.

Meyvis, T., \& Janiszewski, C.(2004) When are broader brands stronger brands? An accessibility perspective on the success of brand extensions. $J$. Consumer Research, 31, 346-357.

Miller, D. (2003) An asymmetry-based view of advantage: towards an attainable sustainability. Strategic Management Journal, Special Issue, 24, 961-976.

Newbert, S. L. (2007) Empirical research on the resource-based view of the firm: an assessment and suggestions for future research. Strategic Management Journal, 28: 121-146.

Pellanda, E. (1937) 25 Annos A. J. Renner \& Cia. Porto Alegre.

Penrose, E. (2006) A teoria do crescimento da firma. (T. Szmrecsányi, Trad.). SP: Unicamp.

Picoli, F., Souza, C. P. \& Takahashi, A. R. W. (2013) Produção nacional em capacidades dinâmicas: um estudo bibliométrico. Encontro da Anpad, 37. RJ.

Porter, M.E. (1986) Estratégia competitiva: técnicas para análise de indústrias e da concorrência. (E. M. P. Braga, Trad.) Rio de Janeiro: Campus.

Priem, R.L., \& Butler, J.E. (2001) Is the resource based "view" a useful perspective for strategic management research? Academy of Management Review, 26 (1), 22-40.

Teece, D., Pisano, G., Shuen, A. (1997) Dynamic capabilities and strategic management. Strategic Management Journal, 18 (7), 509-533.

Wernerfelt, B. (1984) A resource-based view of the firm. Strategic Management Journal, 5 (2), 157170.

Williamson, O. E. (1999) Strategy research: governance and competence perspectives. Strategic Management Journal, 20 (12), 1087-1108.

Winter, S.G. (2003) Understanding dynamic capabilities. Strategic Management Journal, 24 (10), 991-995.

Zollo, M., \& Winter, S.G. (2002) Deliberate learning and the evolution of dynamic capabilities. Organization Science, 13 (3), 339-351. 